\title{
Multi-objective solution with PSO algorithm for minimization of torque ripple and speed settling time by using solar-fed 11,9 and 3-level multi-level inverter with vector control of induction motor
}

\author{
Shashibhushan G. ${ }^{1}$, Savita Sonoli ${ }^{2}$ \\ ${ }^{1}$ Department of ECE, Sir MVIT, Bangalore, Karnataka, India \\ ${ }^{2}$ Department of ECE, RYM Engineering College, Ballari, Karnataka, India
}

\section{Article Info}

Article history:

Received Dec 2, 2018

Revised Nov 22, 2019

Accepted Jan 13, 2020

Keywords:

Multilevel inverter

Multilevel space vector pulse

Width modulation

PSO algorithm

Torque ripple reduction

\begin{abstract}
The 11,9 \& 3-level cascaded multi-level inverter is fed with vector control of induction motor. The speed performance of the machine is dependent on the PI controller used for speed control. Regulation of speed can go till $5 \%$ is allowable. If the PI controller parameters are not optimal the speed error gets increase. The torque ripple can be reduced by using the multilevel inverter. More than that the PI controller output is related with torque. So, the problem is formulated with reduction of settling time of speed and torque ripple. The Multi-objective Particle Swarm Optimization (MPSO) algorithm is used to solve the problem. And the performances are compared with PI controller and PSO-PI control of vector control drive. MATLAB is used to solve the entire system.
\end{abstract}

This is an open access article under the CC BY-SA license.

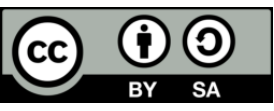

\section{Corresponding Author:}

Shashibhushan G.,

Departement of Electronics and Communication Engineering,

Sir MVIT, Bangalore, Karnataka, India,

Email: shashigadigi1234@gmail.com

\section{INTRODUCTION}

In recent days the speed control of the induction machine needed to be faster and accurate for many sensitive applications. The vector control of induction machine provides better control over speed. The problem in vector control is settling time. To improve the settling time many researches are carried out. In [1] the 5-level cascaded multilevel inverter is used for pumping load. The PI controller is replaced with fuzzy based PSO algorithm in [2] for improving stability. Only type-2 fuzzy is used in [3,4]. PSO tuned PI controller is used in [5] for PMSM machine and in [6] GA-PSO is used for the speed and current control for vector control of induction motor. PSO based online vector control is also carried out in [7]. The vector control of three stage multilevel inverter is discussed in [8]. To reduce the harmonics multilevel inverter is used in vector control technique in [9]. Many new types of inverters are used to control the motor and which are discussed in [10-25].

In this paper Photo-Voltaic (PV) fed cascaded multilevel inverter with 11,9 \&3 level and the speed control of induction motor with vector control using MPSO optimized PI to minimize the settling time and reduce the torque ripple is proposed. 


\section{PROBLEM IDENTIFICATION}

The vector control has a speed control loop with PI controller to produce proportional torque value for electromagnetic torque reference to control the torque of the motor. It can be derived as follows

$$
N_{\text {error }}=N^{*}-N
$$

When applied to PI controller it can be defined as

$$
T_{e}=\left(K_{p}+\int_{T_{e, \min }}^{T_{e, \max }} K_{i}\right) * N_{\text {error }}
$$

So, the torque results are totally depending on the $\mathrm{Kp}$ and $\mathrm{Ki}$ values of PI controller. By changing the values of PI controller, the torque ripples can be changed. So, it is formed as a discrete optimization equation with settling time as another objective. So, the problem is formulated as minimization of torque and settling time of speed of the Direct torque Control (DTC) is done by considering an arbitrary limit for Kp and Ki values.

\section{OBJECTIVE FUNCTION}

Objective function used here is done for torque minimization with reduction of settling time of speed. Both the objectives are made as multi-objectives as given in (1)

$$
\begin{aligned}
& F=\min \left\{\sum_{t=0}^{n}\left(\frac{T_{e}(t)}{n}\right) \alpha_{1}+T_{s} \alpha_{2}\right\} \\
& T_{e}(t)-\text { electromechanicaltorqueatsamplet } \\
& n-\text { totalnumberof sample } \\
& T_{s}-\text { speedsettlingtimeinsec } \\
& \alpha_{1}, \alpha_{2}-\text { weightvaluesformultiobjectivefunction }
\end{aligned}
$$

Constraints

$$
\begin{aligned}
& K_{p, \text { min }}<K_{p}<K_{p, \max } \\
& K_{i, \text { min }}<K_{i}<K_{i, \text { max }}
\end{aligned}
$$

\section{MULTI-OBJECTIVE PARTICLE SWARM OPTIMIZATION}

MPSO is based on the behavior of the food search in a group of fish or bees or birds. The procedure of the algorithm is given as follows.

Step 1. Assume the size of the swarm or particle (m). usually size of 20 to 30 particles are used. Step 2. Generate the initial population of $\mathrm{X}$ in the range $\mathrm{X}(\mathrm{l})$ and $\mathrm{X}(\mathrm{u})$ randomly as $\mathrm{X} 1, \mathrm{X} 2, \ldots \mathrm{XN}$. Step 3. Evaluate the objective function value using (3).

Step 4. Find the velocities of particles. All velocities are initially assumed as zero. All particles move towards the optimal point.

Step 5. Find the historical best value of the particles, which is known as local best, or particle best (Pbest) and find the best particles of all the previous iterations called as global best or Gbest. Find the velocities of the particles $\mathrm{j}$ in ith iteration as follows,

$$
\mathrm{Vj}(\mathrm{i})=\mathrm{Vj}(\mathrm{i}-1)+\mathrm{c} 1 \mathrm{r} 1[\text { Pbest }-\mathrm{Xj}(\mathrm{i}-1)]+\mathrm{c} 2 \mathrm{r} 2[\text { Gbest-Xj(i-1)] }
$$

Where,

$\mathrm{j}=1,2, \ldots \mathrm{N}$.

$\mathrm{c} 1, \mathrm{c} 2=$ learning factor assumed as 2

$\mathrm{r} 1, \mathrm{r} 2=$ Uniformly distributed random numbers range 0

and 1 . Now find the position or coordination of the jth particle in the ith iteration

$$
\mathrm{Xj}(\mathrm{i})=\mathrm{Xj}(\mathrm{i}-1)+\mathrm{Vj}(\mathrm{i})
$$


Now evaluate the objective values of the above $\mathrm{Xj}$.

Step 6. Check the convergence of the current solution, if the positions of all particles converge to the same set of values the method is assumed to have converged else increment the iteration number and evaluate step 5 .

\section{RESULTS AND DISCUSSION}

Figure 1. shows the Eleven level cascaded multi-level inverter fed induction machine with solar MPPT. Figure 2. shows the Convergence of PSO technique. Figure 3 shows the Speed curve of PSO-PI controlled with 11-level,9-level and 3-level vector control. PSO-PI controller pulls the settling time faster compared to PI controller. the PI controller settles in $0.334 \mathrm{sec}$ where as PSO-PI controller settles the speed in 0.325 secs for 11-level. And Figure 4. shows the torque curve of PSO based PI controller vector control. Figure 5. shows the speed curve of PI controller-based vector control Figure 6. shows the torque curve of PI controller-based vector control. It can be seen that the PSO-PI performs faster and with less ripple in torque compared to PI controller. The Speed response of PI and PSO-PI controlled vector-controlled drive, Motor specification, PSO Algorithm parameters are shown in Table 1-3 respectively.

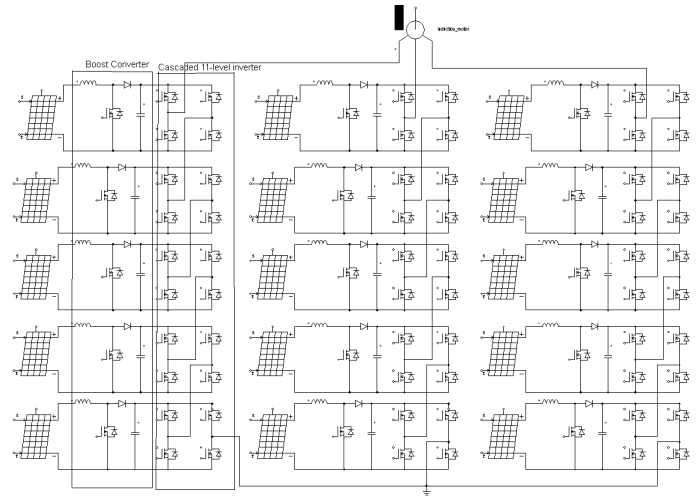

Figure 1. Eleven level cascaded multi-level inverter fed induction machine with solar Maximum PowerPoint

Tracking (MPPT)

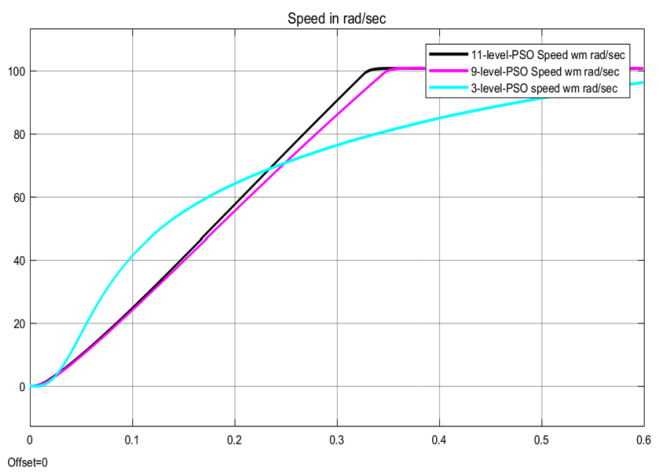

Figure 3. Speed curve of PSO based PI controller vector control

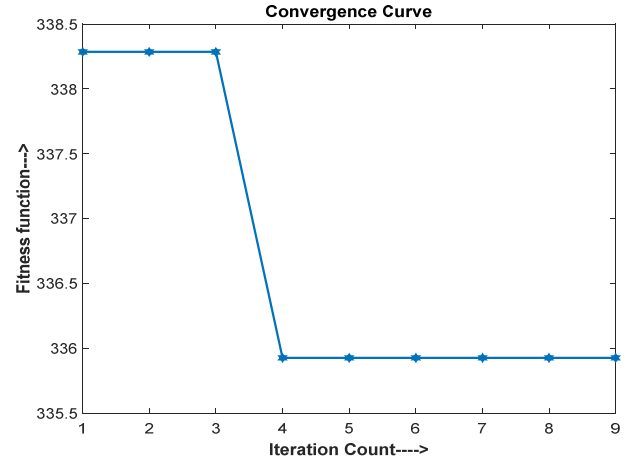

Figure 2. Convergence of PSO technique

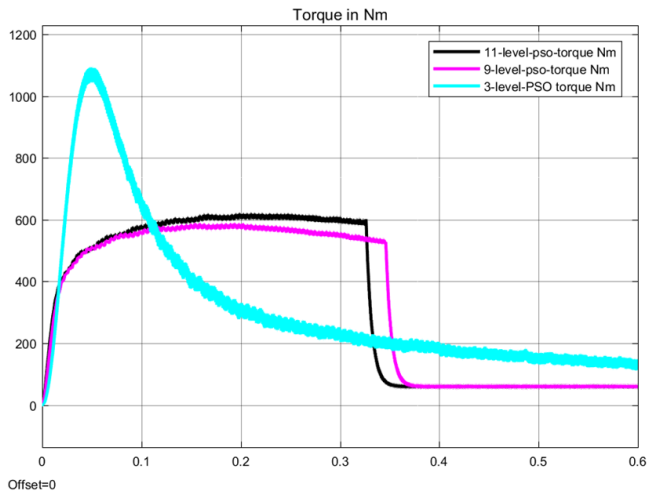

Figure 4. torque curves of PSO based PI controller vector control 


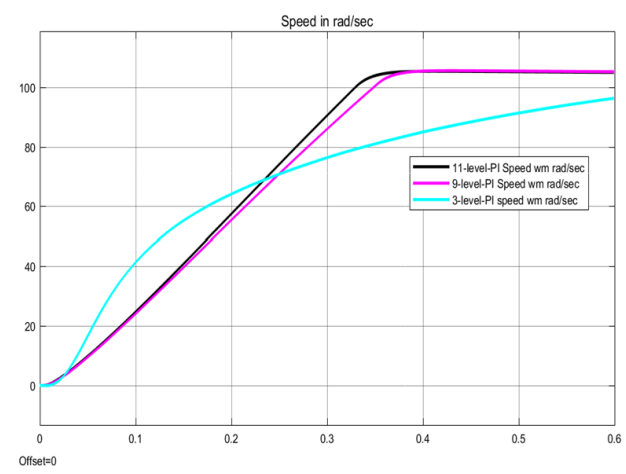

Figure 5. Speed curve of PI controller-based vector control

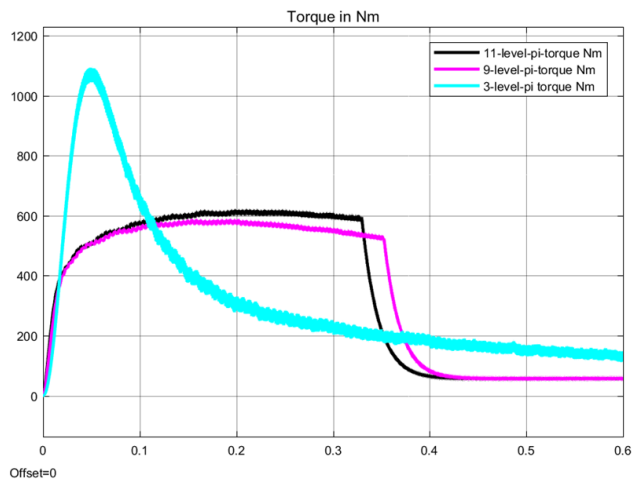

Figure 6. torque curve of PI controller vector control
Table 1. Speed response of PI and PSOPI controlled vector-controlled drive

\begin{tabular}{ccc}
\hline & PI & PSO-PI \\
\hline Rise Time (sec) & 0.25609 & 0.24928 \\
Settling Time (sec) & 0.33421 & 0.32502 \\
Settling Min (rad/sec) & 93.106 & 90.564 \\
Settling Max (rad/sec) & 105.38 & 100.65 \\
Overshoot in \% & 186.93 & 2.114 \\
Undershoot in \% & 5.0487 & 5.1904 \\
Peak (rad/sec) & 105.38 & 100.65 \\
Peak Time in sec & 0.41064 & 1.5337 \\
\hline
\end{tabular}

Table 2. Motor specification

\begin{tabular}{cc}
\hline \multicolumn{2}{c}{ Motor parameters } \\
\hline specifications & Values \\
Nominal power $(\mathrm{VA})$ & 37300 \\
voltage (line-line) $(\mathrm{Vrms})$ & 460 \\
frequency $(\mathrm{Hz})$ & 50 \\
Stator resistance $(\mathrm{ohm})$ & 0.087 \\
Stator inductance $(\mathrm{H})$ & $8.00 \mathrm{E}-04$ \\
Rotor resistance $(\mathrm{ohm})$ & 0.228 \\
Rotor inductance $(\mathrm{H})$ & $8.00 \mathrm{E}-04$ \\
Mutual inductance $\mathrm{Lm}(\mathrm{H})$ & $3.47 \mathrm{E}-02$ \\
Inertia $\left(\mathrm{kg} . \mathrm{m}^{\wedge} 2\right)$ & 1.662 \\
friction factor $(\mathrm{N} . \mathrm{m} . \mathrm{s})$ & 0.1 \\
pole pairs & 2 \\
\hline
\end{tabular}

Table 3. PSO Algorithm parameters PSO algorithm specifications Values range $\min \quad 0$ range max $\quad 550$ swarm size 2 Number of variables 2 iteration $\quad 10$ inertia weight acceleration factors

\section{CONCLUSION}

The 11-level cascaded multi-level inverter fed vector control of induction motor with minimization of torque ripple and minimization of settling time in speed with MPSO tuned PI controller is done with MATLAB simulation. The system settling time improved by .01 secs and surprisingly the rise time is improved with, overshoot of $2.11 \%$, reduced from $187 \%$ compared to PI and PSO-PI. And the $5 \mathrm{rad} / \mathrm{secs}$ speed error in PI controller is over come in PSO-PI control. The PSO-PI control with 11-level multilevel inverters causes improvement in torque ripple reduction.

\section{REFERENCES}

[1] Charles Baby T, Sabah YS and Krishna Prabhakar lal, "Multilevel inverter fed induction motor drive for pumping application," IEEE International Conference on Technological Advancements in Power \& Energy, pp. 85-92, 2015.

[2] Sanjaya Kumar Sahu, T. V. Dixit and D.D. Neema, "Particle swarm optimized fuzzy controller for indirect vector control of multilevel inverter fed induction motor," Neural and Evolutionary Computing, vol. 11, no. 4, pp, 77-85, july 2014, IJCSI

[3] A. Elnady, A. Adam, "Multilevel inverter operated by voltage orientation control," 5th International Conference on Electronic Devices, Systems and Applications (ICEDSA), pp. 1-4, 2016

[4] Giribabu.D, R. Harsha Vardhan, "Multi level inverter fed indirect vector control ofinduction motor using type 2 fuzzy logic controller," International Conference on Electrical, Electronics, and Optimization Techniques (ICEEOT), pp. 2605-2610, 2016.

[5] Ahmed A. Zaki Diab, S. A. Selim and Basem E. Elnaghi, "Particle swarm optimization-based vector control of permanent magnet synchronous motor drive", IEEE NW Russia Young Researchers in Electrical and Electronic Engineering Conference (EIConRusNW), pp. 740-746,2016.

[6] Dong Hwa Kim, "GA-PSO based vector control of indirect three phase induction motor," Applied Soft Computing, vol. 7, pp. 601-611, 2007.

[7] Bhola Jha, et al, "PSO-based online vector-controlled induction motor drives," International Conference on Electrical, Electronics, and Optimization Techniques (ICEEOT), pp. 2234-2239. 2016

[8] Saad Mekhilef, and Mohamad N. Abdul Kadir, "Voltage control of three-stage hybrid multilevel inverter using vector transformation," IEEE Transactions on Power Electronics, vol. 25, no. 10, pp. 2599-2606, Oct. 2010. 
[9] José Rodríguez, Luis Morán, Pablo Correa, and Cesar Silva, "A vector control technique for medium-voltage multilevel inverters," IEEE Transactions on Industrial Electronics, vol. 49, no. 4, pp. 882-888, Aug. 2002.

[10] V. Naumanen J. Korhonen P. Silventoinen J. Pyrho "nen, "Mitigation of high du/dt-originated motor overvoltages in multilevel inverter drives,", IET Power Electronics, vol. 3, no. 5, pp. 681-689, Sep 2010.

[11] A. Chitra, S. Himavathi, "Reduced switch multilevel inverter for performance enhancement of induction motor drive with intelligent rotor resistance estimator," IET Power Electronics, vol. 8, no. 12, pp. 2444-2453, 2015.

[12] Yushan Liu, Baoming Ge, Haitham Abu-Rub, "Modelling and controller design of quasi-Z-source cascaded multilevel inverter-based three-phase grid-tie photovoltaic power system," IET Renewable Power Generation, vol. 8, no. 8, pp. 925-936, 2014.

[13] M.R. Baiju, K. Gopakumar, K.K. Mohapatra, V.T. Somasekhar and L. Umanand, "Five-level inverter voltagespace phasor generation for an open-end winding induction motor drive," IEE Proc.-Electr. Power Appl., vol. 150, no. 5, pp. 531-538, 2003.

[14] Jose Rodríguez, Jorge Pontt, Norbert Becker, and Alejandro Weinstein, "Regenerative drives in the megawatt range for high-performance downhill belt conveyors," IEEE Transactions on Industry Applications, vol. 38, no. 1, pp. 203-210, 2002.

[15] AmarendraEdpuganti \& Akshay K. Rathore, "A Survey of Low-Switching Frequency Modulation Techniques for Medium-Voltage Multilevel Converters," IACC, vol. 51, no. 5, pp. 4212-4228, 2015.

[16] R. Guruprasath, R. Dhivya, "Comparision betweeen symmetric \& new model asymmetric Z-source cascaded multilevel inverter fed IM for Selective harmonic minimization \& THD reduction with PV cell input," ICEETS 2013, Pp. 1347-1353, 2013

[17] Nupur Mittal, Bindeshwar Singh, S.P Singh, Rahul Dixit, and Dasharath Kumar, "Multilevel Inverters: A Literature Survey on Topologies and Control Strategies", 2012 2nd International Conference on Power, Control and Embedded Systems, pp. 1-11, 2012.

[18] RamuluChinthamalla, K. Shivaji Ganesh and Sachin Jain, "An optimal and efficient pv system using two 2-level cascaded 3-level inverter for centrifugal pump," 2014 IEEE International Conference on Power Electronics, Drives and Energy Systems (PEDES), pp. 1-6, 2014.

[19] B. Housseini, R. Beguenane, F. A. Okou, M. A. Tankari, "Advanced multilevel control strategy for induction motor drive: Utilization of PV-battery standalone system and total harmonic distortion analysis", 2012 International Symposium on Power Electronics, Electrical Drives, Automation and Motion, pp. 231-236, 2012.

[20] Bailu Xiao, Lijun Hang, Jun Mei, Cameron Riley, Leon M. Tolbert, BurakOzpineci, "Modular Cascaded H-Bridge Multilevel PV Inverter with Distributed MPPT for Grid-Connected Applications," IEEE Transactions on Industry Applications, vol. 51, no. 2, pp. 1722-1731, March-April 2015.

[21] V. T. Somasekhar, K. Gopakumar, M. R. Baiju, Krishna K. Mohapatra, and L. Umanand, "A Multilevel Inverter System for an Induction Motor with Open-End Winding," IEEE Transactions on Industrial Electronics, vol. 52, no. 3, pp. 824-836, June 2005.

[22] Anandarup Das, K. Sivakumar, RijilRamchand, Chintan Patel and K. Gopakumar, "A Combination of Hexagonal and 12-Sided Polygonal Voltage Space Vector PWM Control for IM Drives Using Cascaded Two-Level Inverters," IEEE Transactions on Industrial Electronics, vol. 56, no. 5, pp. 1657-1664, May 2009.

[23] K. Sivakumar, Anandarup Das, RijilRamchand, Chintan Patel and K. Gopakumar, "A Hybrid Multilevel Inverter Topology for an Open-End Winding Induction-Motor Drive Using Two-Level Inverters in Series with a CapacitorFed H-Bridge Cell,” IEEE Transactions on Industrial Electronics, vol. 57, no. 11, pp. 3707-3714, Nov. 2010.

[24] Javier Chavarría, Domingo Biel, FrancescGuinjoan, Carlos Meza, and Juan J. Negroni, "Energy-Balance Control of PV Cascaded Multilevel Grid-Connected Inverters Under Level-Shifted and Phase-Shifted PWMs," IEEE Transactions on Industrial Electronics, vol. 60, no. 1, pp. 98-111, Jan. 2013.

[25] Anubrata Dey, P. P. Rajeevan, RijilRamchand, K. Mathew, and K. Gopakumar, "A Space-Vector-Based Hysteresis Current Controller for a General n-Level Inverter-Fed Drive with Nearly Constant Switching Frequency Control," IEEE Transactions on Industrial Electronics, vol. 60, no. 5, pp. 1989-1998, May 2013. 


\section{BIOGRAPHIES OF AUTHORS}

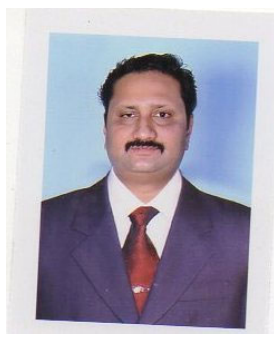

Shashibhushan G with 12 years experience in academics is currently working as the Assistant Professor in Sir MVIT, Bangalore. He completed his B.E from RYMEC, Ballari, Karnataka, India in the year 1999 and M.Tech from PDA College of Engineering, Gulbarga, and Karnataka, India in the year 2005. His research interests include Power Electronics and Embedded System. $\mathrm{He}$ has published 10 Journals in Power Electronics, Image Processing and Communication Systems.

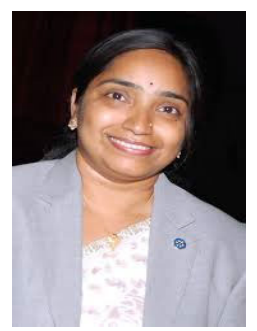

Dr. Savita Sonoli completed her B.E in Electronics and Communications engineering from BVB College of Engineering and technology,Hubli,karnataka,India in 1995,M.Tech in National Institute of Technology,Surathakal,karnataka ,India in 1998 and her PhD from S.K University ,Anantapur, Andhra pradesh, India in 2009 . Having a vast Professional experience of 20 years which includes 15 years of administrative experience, she is now working as the Vice Principal and Profesor in Electronics and Comunication Engineering in RYMEC,Ballari, Karnataka, India.She has published around 21 papers in her research área of embedded systems including both national and international levels.Her research interests include Power Management, Image Processing and Embedded Systems. 